\title{
Anatomical Variations in Patients with Ménière Disease: A Tomography Study
}

\author{
Lucas Resende Lucinda ${ }^{1}$ Daniela Dranka Cristoff ${ }^{2}$ Luiz Otávio De Mattos Coelho ${ }^{3}$ \\ Otávio Pereira Lima Zanini ${ }^{4}$ Rita De Cassia Cassou Guimarães ${ }^{1}$
}

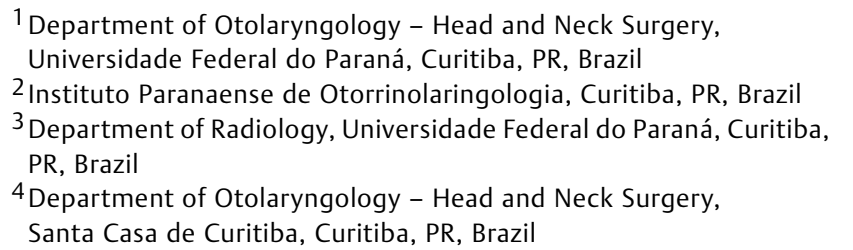

Address for correspondence Lucas Resende Lucinda, MD, Department of Otorhinolaryngology - Head and Neck Surgery, Hospital de Clínicas, Universidade Federal do Paraná. Rua General Carneiro, 181, Curitiba, PR 80060-900, Brazil (e-mail: lucasresendelucinda@gmail.com).

Int Arch Otorhinolaryngol 2018;22:231-238.

\begin{abstract}
Keywords

- Ménière disease

- temporal bone

- x-ray computed tomography

Introduction The etiology of Ménière disease (MD), a difficult-to-treat condition with great morbidity, remains controversial in the literature. The possible clinical and diagnostic impact of anatomical variations of the temporal bone among patients with MD has been recently studied.

Objective To identify anatomical variations of the temporal bone associated with the diagnosis of MD.

Methods Thirty-seven patients were included, although each ear was considered separately $(n=74)$. A case group $(n A=33)$ was composed of the affected ears of patients with definite MD and a control group $(n B=41)$ was used consisting of the ears of individuals who did not meet the criteria for MD and of the contralateral ears from patients with unilateral disease. Tomographic images from the individuals included in the study were submitted to a blinded and systematic evaluation regarding a broad variety of anatomical variations of the temporal bone. Obtained data were compared statistically between the groups and after stratifying the study sample. Significance level was set at 0.05 .

Results Among the affected ears, it was observed an increased number of tomographic scans in which the vestibular aqueduct could not be identified ( $p=0.01$, Fisher exact test). No statistically significant differences were observed when comparing the affected and contralateral ears from patients with unilateral MD, between affected ears from patients with unilateral and bilateral disease or between contralateral ears of patients with unilateral affection and patients without the disease.

Conclusion Some anatomical variations might be more frequent in the affected ears of patients with MD, such as the lower rates of individualization of the vestibular aqueduct.
\end{abstract}

received

April 18, 2017

accepted

June 9, 2017

published online

August 28, 2017
DOI https://doi.org/

10.1055/s-0037-1604463. ISSN 1809-9777.
Copyright $(2018$ by Thieme Revinter

Publicações Ltda, Rio de Janeiro, Brazil
License terms

(ㄷ) (i) $\ominus$ (5) 


\section{Introduction}

Ménière disease (MD) is a chronic disease affecting the inner ear. It was first described, in 1861, by Prosper Ménière, and it is broadly characterized by intermittent episodes of vertigo, fluctuating hearing loss, tinnitus and aural fullness. ${ }^{1,2}$

Data concerning the incidence and prevalence of MD are scarce and uncertain. ${ }^{3}$ Prevalence estimates ranges from 10 to 150 per 100,000 individuals. ${ }^{4}$ Most of the studies suggest a slight preponderance of the disease among women ( 1.3 women per each affected man). ${ }^{5}$ Ménière disease also seems more frequent among adults in their fourth or fifth decades of life and positive family history is extremely common. ${ }^{6,7}$

The diagnosis of Ménière disease remains eminently clinical. ${ }^{8}$ Its clinical presentation is widely variable. Many patients present with audiological symptoms, some have mostly vestibular complaints and others show a combination of audiovestibular manifestations. ${ }^{9}$ Bilateral involvement might be seen in $10-50 \%$ of the patients, leading to a difficult-to-treat condition with more disabling symptoms and unfavorable prognosis. ${ }^{10}$ In 2015, the Classification Committee of the Bárány Society, the Japan Society for Equilibrium Research, the European Academy of Otology and Neurotology (EAONO), the Equilibrium Committee of the American Academy of Otolaryngology-Head and Neck Surgery (AAO-HNS) and the Korean Balance Society jointly revised the diagnostic criteria and established a new classification for MD. $(- \text { Table } \mathbf{1})^{11}$ These criteria remain as the main diagnostic tool for MD in clinical practice.

However, some authors report that evidences of endolymphatic hydrops, obtained in particular complementary investigation methods with growing sensibility and specificity, might be helpful in patients with MD in its early stage or those with mild and non-specific symptoms.

The possibility of clinical implications of the anatomical variations of the temporal bone among patients with MD has been targeted in some studies. Recent technological advances, unique special resolution and wide availability have made high resolution computed tomography (HRCT) of the temporal bone the main imaging modality in otology. ${ }^{12}$ High resolution computed tomography is capable of detecting anatomical correlations between the structures of the inner ear, including surrounding vascular components. As a result, it can define, with high sensibility and specificity rates, anatomical variations which, among patients with MD, might serve as clinical markers that could underpin the diagnosis of this condition or play a role in its pathophysiology.

No radiological sign is deemed specific for MD. Previous studies have shown higher prevalence of some anatomical variations in the temporal bones of affected individuals, although they vary significantly in terms of the variables evaluated, the radiological method employed and the stratification of the sample. Yet, there are few researches including patients with bilateral MD.

This present study aims to identify anatomical variations of the temporal bone which might be associated with unilateral and/or bilateral MD.

\section{Methods}

This is a case-control study. All included participants $(n=37)$ attended ambulatories of otoneurology in a public tertiary hospital and a specialized clinic in Curitiba, Brazil, and underwent a computed tomography (CT) of the temporal bone as a complementary evaluation. For the study, each ear was considered separately $\left(n_{\text {final }}=74\right)$. Hence, a case group (group A, $n_{\mathrm{A}}=33$ ) consisted of the affected ears of patients with clinical diagnosis of unilateral or bilateral MD, according to the new criteria proposed by international societies in 2015, which includes, by definition, suggestive and audiometrically documented hearing loss. A control group (group $\mathrm{B}, n_{\mathrm{B}}=41$ ) included the ears of individuals attending the same clinics, although without criteria for either probable or definite MD and presenting a normal audiometry, as well as the contralateral ears of the patients with unilateral MD included in the case group. Patients under 18 years of age or with history of inflammatory otitis media, temporal bone neoplasm or trauma, congenital ear anomalies or previous otologic surgery were excluded from the sample. All included participants signed a free and informed consent form. The project was approved and registered by the Institutional Ethics Committee (CAAE number, 54235316.9.0000.0096).

Table 1 Diagnosis criteria and classification of Ménière disease according to the Classification Committee of the Bárány Society, the Japan Society for Equilibrium Research, the European Academy of Otology and Neurotology (EAONO), the Equilibrium Committee of the American Academy of Otolaryngology-Head and Neck Surgery (AAO-HNS) and the Korean Balance Society ${ }^{11}$

DIAGNOSIS CRITERIA FOR MÉNIÈRE DISEASE
Definite Ménière disease:
- Two or more spontaneous vertigo episodes, each of them lasting from 20 minutes to 12 hours.
- Audiometrically documented low- to medium- frequency sensorineural hearing loss in one ear, defining the affected ear
on at least one occasion before, during or after one of the episodes of vertigo.
- Fluctuating aural symptoms (hearing loss, tinnitus, aural fullness) in the affected ear
- Not better accounted for by another vestibular diagnosis
Probable Ménière disease:
- Two or more spontaneous vertigo episodes, each of them lasting from 20 minutes to 12 hours.
- Fluctuating aural symptoms (hearing loss, tinnitus, aural fullness) in the affected ear
- Not better accounted for by another vestibular diagnosis


Table 2 Variables individually investigated in each ear of this study's sample

\begin{tabular}{|l|l|}
\hline Anatomical Aspect & \multicolumn{2}{l}{$\begin{array}{l}\text { Categories/Unity of Measurement } \\
\text { for the Variable }\end{array}$} \\
\hline Categorical Variables & High or normal \\
\hline Height of the jugular bulb considering the basal turn of the cochlea & Present or absent \\
\hline $\begin{array}{l}\text { Presence of any of the major anatomical variations of the jugular bulb: } \\
\text { diverticulum, dehiscence to the middle ear or otic capsule, } \\
\text { contact with cochlear or vestibular aqueducts }\end{array}$ & \multicolumn{2}{|l|}{ Above or below the basal turn of the cochlea } \\
\hline Position of the aperture opening of the vestibular aqueduct & More or less than half of its extension \\
\hline Individualization of the cochlear aqueduct & Absent/decreased or increased \\
\hline Pneumatization of the retrolabyrinthine space & Absent/decreased or increased \\
\hline Pneumatization of the supralabyrinthine space & Absent/decreased or increased \\
\hline Pneumatization of the infralabyrinthine space & Absent/decreased or increased \\
\hline Pneumatization of the petrous apex & \multicolumn{2}{|l}{} \\
\hline Continuous Variables & In millimeters (mm) \\
\hline Anteroposterior diameter of the jugular bulb & In millimeters (mm) \\
\hline Transverse diameter of the jugular bulb & In millimeters (mm)) \\
\hline Size of the vestibular aqueduct (if visible) & In grades ${ }^{\circ}$ ) \\
\hline Inclination angle between the vestibular aqueduct and the vestibule & \\
\hline
\end{tabular}

The tomographic images were obtained in a matrix of $512 \times 512$ pixels, in high resolution, between 2014 and 2016. The HRCT scans provided volumetric images in the axial plane, which were transferred to a workstation for postprocessing. These data were reformatted in the axial and coronal planes using specific software, yielding images with $1 \mathrm{~mm}$ section thickness on each side individually.

Clinical and epidemiological data were collected from the participants and their images were assessed by a single radiologist specialized in temporal bone evaluation, without previous knowledge of their clinical history or physical examination. Anatomical aspects regarding region-specific temporal bone pneumatization, the jugular bulb and the positioning and structure of the cochlear and vestibular aqueducts were systematically analyzed. (-Table 2, - Fig. 1)

The results from the case and control groups were confronted. A secondary assessment of the case group was performed after its stratification into two subgroups: one $\left(\mathrm{A} 1, n_{\mathrm{A} 1}=13\right)$ composed by the affected ears of patients with unilateral MD and another by the ears of those with bilateral disease (A2, $\left.n_{\mathrm{A} 2}=20\right)$. The control group was also divided into two subgroups, which had their data compared as well: one (B1, $\left.n_{\mathrm{B} 1}=13\right)$ formed by asymptomatic contralateral ears of individuals with unilateral MD and another (B2, $n_{\mathrm{B} 2}=28$ ) consisting of individuals without MD and normal audiometric evaluation. ( - Fig. 2). Results from subgroups A1 and B1 were also confronted.

The Pearson chi-square and Fisher exact tests were employed to evaluate categorical variables. Continuous variables were assessed using the Wilcoxon-Mann-Whitney. Statistical analysis was performed using the Statistical Package for Social Science (SPSS). Significance level was set at 0.05.

\section{Results}

There was no statistical difference between the study groups in terms of age or sex ( $p>0.05$, data not shown).

The comparison between the results from the case (A) and control (B) groups is summarized in - Fig. 3. There was a significant correlation between MD in only one of the variables assessed: capacity of individualization of the vestibular aqueduct (VA). Among patients with MD, this structure was observed less frequently ( $p=0.01$; Fisher exact test).

- Table 3 shows the statistical significance level obtained when analyzing subgroups $\mathrm{A} 1$ and $\mathrm{A} 2$, which were composed by the affected ears of patients with unilateral and bilateral $\mathrm{MD}$, respectively. None of the variables was significantly associated with the occurrence of bilateral disease $(p<0.05)$.

The results from the statistical analysis between subgroups consisting of the affected (A1) and healthy contralateral (B1) ears of patients with MD are provided in - Table 4. Similarly, there was no significant difference for any of the variables investigated.

-Fig. 4 reports statistical data regarding the results when comparing the control subgroups (B1 and B2). There was a trend toward lower angulation between the vestibular aqueduct and the vestibule in the contralateral ears of patients with unilateral disease, when compared with the ears of individuals without MD $(p=0.11)$. Nonetheless, none of the variables reached statistical significance $(p<0.05)$.

\section{Discussion}

One previous study has suggested that the sigmoid sinus could be placed significantly more anteriorly and medially in 

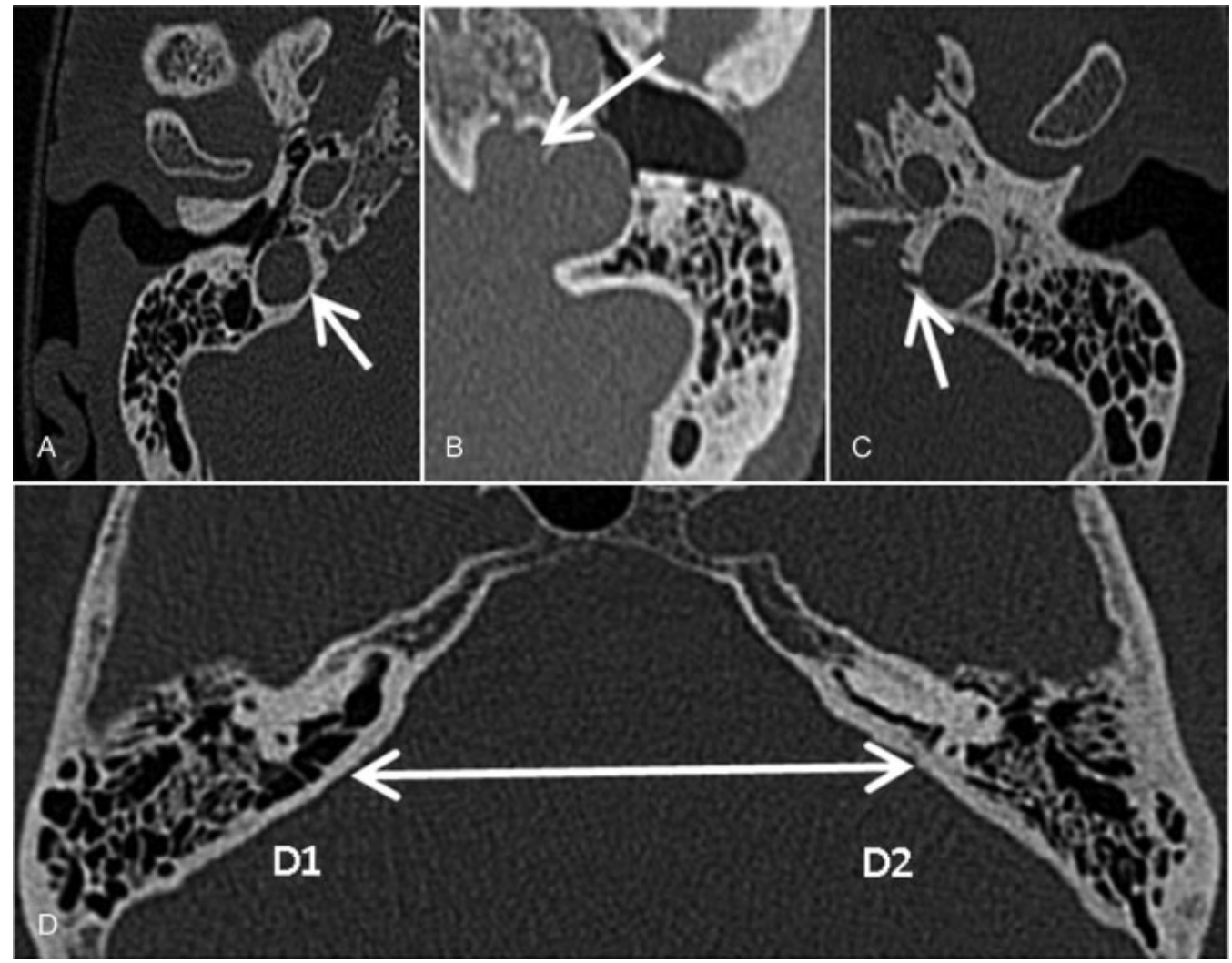

Fig. 1 Computed axial tomography images showing anatomical variations of the temporal bone: (A) High jugular bulb, above the level of the tympanic annulus (arrow); (B) Jugular bulb diverticulum (arrow); (C) Contact between the jugular bulb and the vestibular aqueduct (arrow); (D) Asymmetric pneumatization of the retrolabyrinthine space, deemed increased on the right (D1) and decreased on the left side (D2) (arrow). Source: the author.

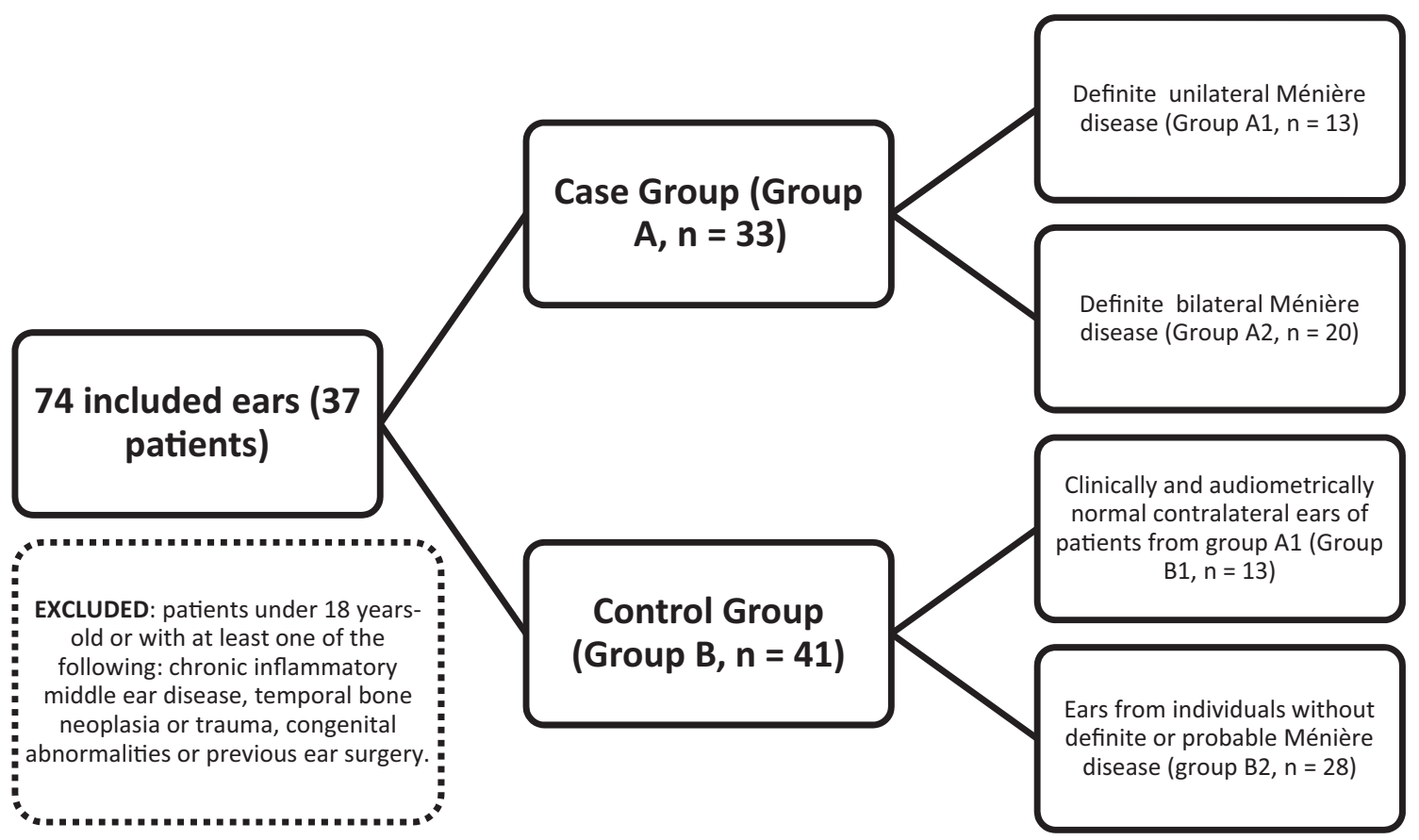

Fig. 2 Study flow chart. 


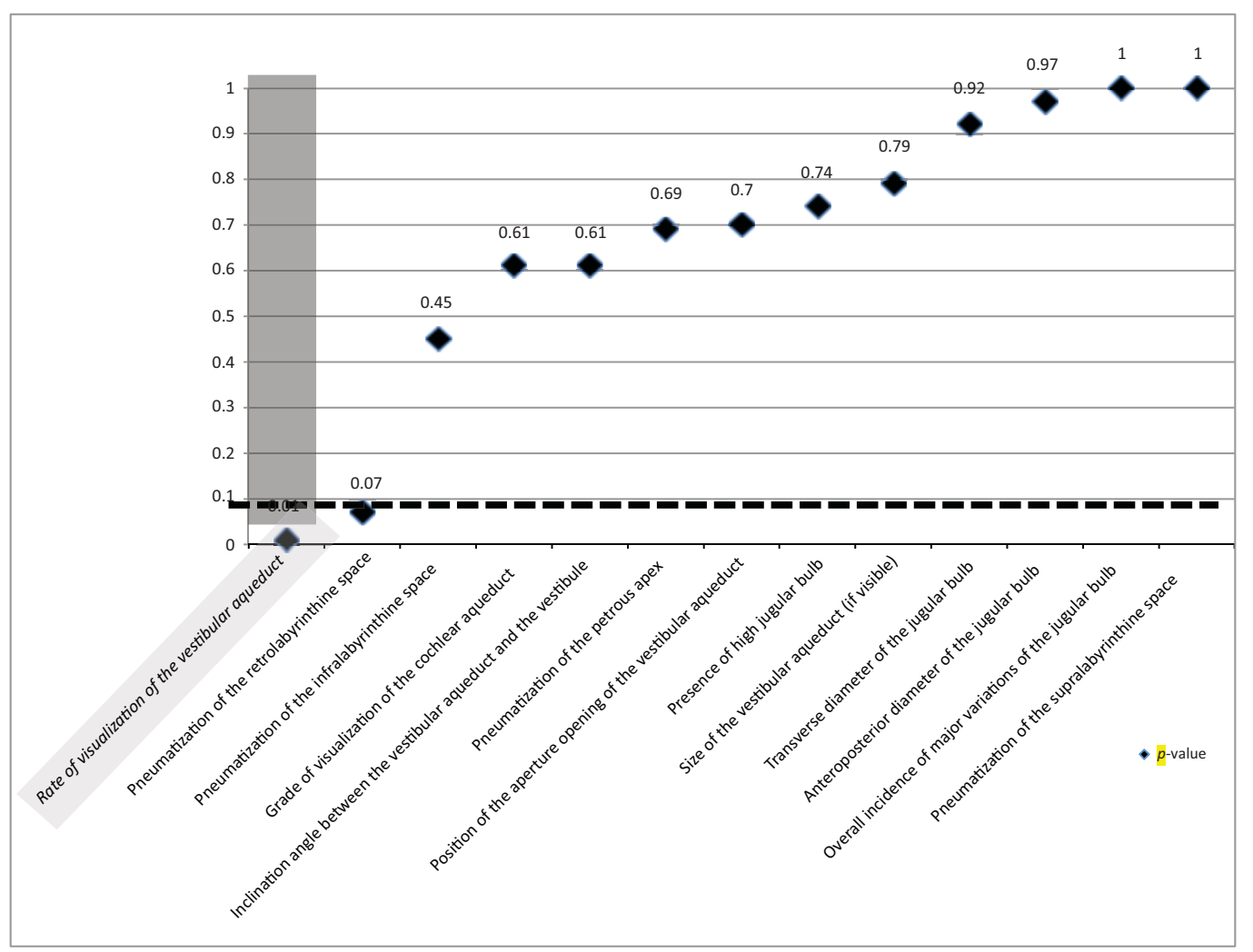

Fig. 3 Values (p) for each assessed variable resultant from comparative statistical analysis between the main study groups, case (A) and control (B). Significance level: $p$-value $<0.05$.

Table 3 A summary of statistical data ( $p$-value) obtained for each variable after assessing both case subgroups. Comparison between data of affected ears from patients with unilateral disease (subgroup A1) and those of individuals with bilateral disease (subgroup A2)

\begin{tabular}{|l|l|}
\hline Variable & $p$-value \\
\hline Presence of high jugular bulb & $0.41\left(\mathrm{X}^{2}\right)$ \\
\hline $\begin{array}{l}\text { Anteroposterior diameter of the } \\
\text { jugular bulb }\end{array}$ & 0.41 (WCX) \\
\hline Transverse diameter of the jugular bulb & 0.17 (WCX) \\
\hline $\begin{array}{l}\text { Overall incidence of major variations } \\
\text { of the jugular bulb }\end{array}$ & 0.63 (Fisher) \\
\hline $\begin{array}{l}\text { Rate of visualization of the } \\
\text { vestibular aqueduct }\end{array}$ & 0.13 (Fisher) \\
\hline Size of the vestibular aqueduct (if visible) & 1.0 (WCX) \\
\hline $\begin{array}{l}\text { Position of the aperture opening of } \\
\text { the vestibular aqueduct }\end{array}$ & 1.0 (Fisher) \\
\hline $\begin{array}{l}\text { Inclination angle between the } \\
\text { vestibular aqueduct and the vestibule }\end{array}$ & 0.57 (WCX) \\
\hline $\begin{array}{l}\text { Grade of visualization of the } \\
\text { cochlear aqueduct }\end{array}$ & 1.0 (Fisher) \\
\hline Pneumatization of the infralabyrinthine space & 0.73 (Fisher) \\
\hline Pneumatization of the retrolabyrinthine space & 0.21 (Fisher) \\
\hline Pneumatization of the supralabyrinthine space & 1.0 (Fisher) \\
\hline Pneumatization of the petrous apex & 1.0 (Fisher) \\
\hline
\end{tabular}

Abbreviations: Fisher, Fisher exact test; WCX, Wilcoxon-Mann-Whitney test; $x^{2}$ : chi-square test.

Significance level: $p$-value $<0.05$ patients with MD. The authors hypothesized that the anomalous position of the vessel could generate compression of the endolymphatic sac and, therefore, hydrops. ${ }^{13}$

The jugular bulb consists of a dilation of the internal jugular vein and is located at the posterior part of the jugular foramen. When enlarged, it might be responsible for audiovestibular symptoms. ${ }^{14}$ Variations in its size and location are common and might occur due to malformations in the surrounding bony structure or in the intracranial venous system itself or secondary to lack of pneumatization of the mastoid portion of the temporal bone. If the jugular bulb is located superiorly to the inferior surface of the tympanic annulus in the middle ear, at the level of the basal cochlear turn or less than $2 \mathrm{~mm}$ from the inner auditory channel, it is classified as a high jugular bulb $(\mathrm{HJB}){ }^{15,16}$ Most of the previous studies that aimed to evaluate HJB have shown limitations, such as emphasis on its incidence or small samples. ${ }^{17}$ Radiological and post-mortem studies of the temporal bone report a prevalence of $\mathrm{HJB}$ ranging from 3-24\% of the population, although this variation might not be clinically apparent. $^{15,17-19}$ Jugular bulb abnormalities have also been implied in a various range of cochleovestibular symptoms, depending on the impact on the surrounding structures. The jugular bulb might erode into the middle ear or into the cochlear or vestibular aqueducts. Hearing loss, vertigo and tinnitus have also been attributed to high and dehiscent jugular bulbs, as well as to the compressive effects of HJB on the endolymphatic sac. ${ }^{18,20}$ A recent German retrospective controlled study has shown a significantly higher prevalence of jugular bulb abnormalities among patients with MD. The authors concluded that the 


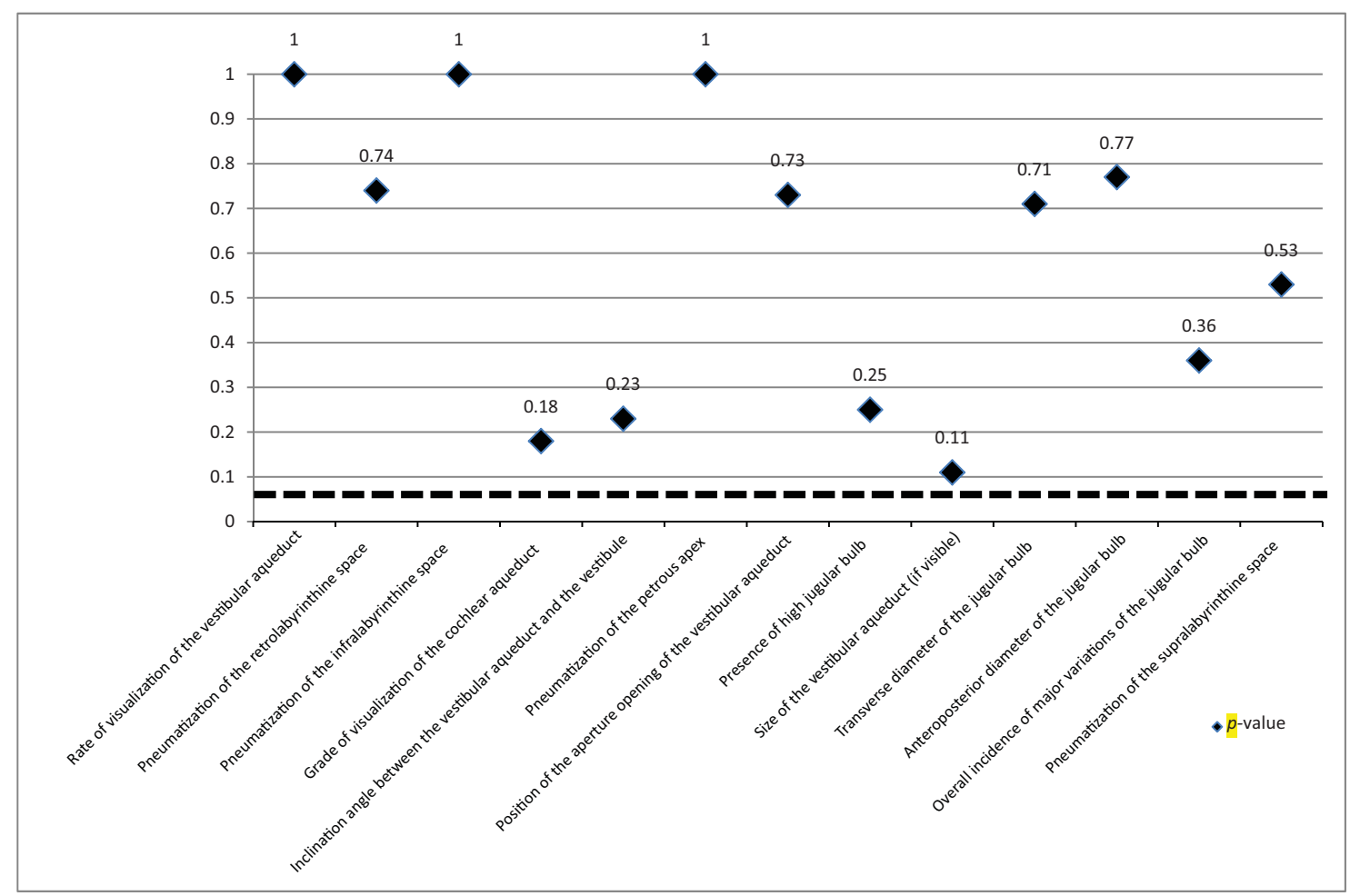

Fig. 4 Results obtained after stratifying the control group: $p$-value associated with each variable, when comparing the results from the contralateral ears of patients with unilateral MD (subgroup B1) and those from individuals without the disease (subgroup B2). Significance level: p-value $<0.05$.

Table 4 A summary of statistical data ( $p$-value) obtained for each variable when comparing the results of affected ears from patients with unilateral Ménière disease (subgroup A1) and those of the contralateral ears of these individuals. (subgroup B1)

\begin{tabular}{|l|l|}
\hline Variable & $p$-value \\
\hline Presence of high jugular bulb & $1.0\left(\mathrm{x}^{2}\right)$ \\
\hline $\begin{array}{l}\text { Anteroposterior diameter } \\
\text { of the jugular bulb }\end{array}$ & $0.82(\mathrm{WCX})$ \\
\hline Transverse diameter of the jugular bulb & 0.45 (WCX) \\
\hline $\begin{array}{l}\text { Overall incidence of major } \\
\text { variations of the jugular bulb }\end{array}$ & 0.66 (Fisher) \\
\hline $\begin{array}{l}\text { Rate of visualization of the } \\
\text { vestibular aqueduct }\end{array}$ & 1.0 (Fisher) \\
\hline Size of the vestibular aqueduct (if visible) & 0.48 (WCX) \\
\hline $\begin{array}{l}\text { Position of the aperture opening } \\
\text { of the vestibular aqueduct }\end{array}$ & 1.0 (Fisher) \\
\hline $\begin{array}{l}\text { Inclination angle between the } \\
\text { vestibular aqueduct and the vestibule }\end{array}$ & 0.96 (WCX) \\
\hline $\begin{array}{l}\text { Grade of visualization of the cochlear } \\
\text { aqueduct }\end{array}$ & 1.0 (Fisher) \\
\hline Pneumatization of the infralabyrinthine space & 0.69 (Fisher) \\
\hline Pneumatization of the retrolabyrinthine space & 1.0 (Fisher) \\
\hline Pneumatization of the supralabyrinthine space & 1.0 (Fisher) \\
\hline Pneumatization of the petrous apex & 1.0 (Fisher) \\
\hline
\end{tabular}

Abbreviations: Fisher: Fisher exact test; WCX: Wilcoxon-Mann-Whitney test; $x^{2}$ : chi-square test.

Significance level: $p$-value $<0.05$. temporal bone in these individuals might be constitutionally different and carry predisposing factors for the development of clinically overt MD. ${ }^{21}$ Redfern et al have also described higher prevalence of abnormalities of the jugular bulb in patients with $\mathrm{MD}$, when compared with the general population. ${ }^{22}$ In the present study, differences in the prevalence of $\mathrm{HJB}$ or major jugular bulb abnormalities among affected ears have not been found.

Ikeda e Sando have shown in a study with post-mortem temporal bones that patients with MD have smaller tubeshaped endolymphatic ducts, in contrast with normal subjects, whose ducts were bigger and funnel-shaped. ${ }^{23}$ Welling et al reported that, in MD, the identification of the endolymphatic duct on magnetic resonance imaging (MRI) could be significantly less frequent compared with controls. In this study, the authors also compared the measurements of the temporal bone in the region of the endolymphatic duct and found smaller dimensions among affected individuals. ${ }^{24}$ By using a systematic approach to the evaluation of CT scans, Alvarenga et al achieved identification rates of the vestibular aqueduct superior to $90 \%$ among both ears of patients with unilateral MD. The rates did not differ statistically from those of control individuals. ${ }^{25}$ In the present study, among affected ears, there was a significantly greater number of CT scans in which the vestibular aqueduct could not be individualized $(p=0.01)$. However, considering only the exams in which this structure was identified, the absolute measurements did not differ from those of the control arm. No statistically significant difference between the study groups was obtained regarding either the position of the internal 
aperture or the inclination of the vestibular aqueduct. Rates of identification of the cochlear aqueduct were also similar. As to the assessment of pneumatization of different portions of the temporal bone, a trend to reduced ( $p=0.07$, Pearson chi-square test) pneumatization of the retrolabyrinthine space was observed among subjects with MD, although this result could not be deemed statistically significant. No difference was demonstrated in the pneumatization of the petrous apex, infralabyrinthine and supralabyrinthine spaces.

Previous functional studies have shown the presence of abnormal findings in the contralateral ears of patients with unilateral MD. ${ }^{26,27}$ These findings have been corroborated by histopathologic studies, which have identified significantly more damage in the contralateral inner ears of patients with MD compared with those of normal controls. ${ }^{28}$ The incidence of functional contralateral involvement and development of clinically apparent bilateral MD increases linearly, so that after 30 years of follow-up, up to $50 \%$ of the patients have bilateral disease. $^{29}$ Increasing evidence of endolymphatic hydrops in asymptomatic contralateral ears might suggest that MD is a systemic disease. ${ }^{30,31}$ Hence, the recurrent findings in the literature of abnormal anatomical features among both affected and contralateral ears in comparison to normal controls might indicate that MD has a complex pathophysiology, in which the anatomical component might be a marker of disease progression or a contributing factor. Accordingly, the previous existence or the development during follow-up of certain anatomical abnormalities in the asymptomatic contralateral ear could predispose the patient to the progression to bilateral disease, with an unfavorable prognosis. Karatas et al studied the size and width of the endolymphatic duct and the presence of jugular bulb abnormalities in the CT scans of patients with unilateral MD. In this study, the measurements for the endolymphatic duct were reported to be smaller and the prevalence of abnormalities of the jugular bulb was higher among MD patients when compared with healthy controls. However, for none of the variables, there was a significant difference between the results of affected and contralateral non-affected ears. ${ }^{32}$ Hall et al also described lower periaqueductal pneumatization rates in the CT scans of patients with MD. Similarly, in this study, the results from the contralateral ears did not differ from those of the affected ears. ${ }^{33}$ Using MRI and CT to evaluate the cochlear aqueduct, Park et al found similar bony dimensions among the affected ears of patients with MD when compared with a control group, although fluid length within this structure was significantly decreased among case subjects. These findings could not be reproduced when comparing the affected and nonaffected ears of patients with MD. ${ }^{34}$

In this work, no statistically significant difference in the prevalence of any anatomical variations was observed when comparing the affected ears of individuals with unilateral MD with those of patients with bilateral MD. Thus, the anatomical factor, if important in MD's pathophysiology and/or diagnosis approach, might contribute independently of the existence of involvement of both ears. There was no difference when comparing the results from the affected and the contralateral non-affected ears of patients with unilateral MD and from these contralateral non-affected ears with the ears of healthy controls. This finding would indicate that the contralateral ears did not differ from the affected ears or from the ears of healthy subjects. Longitudinal and cohort studies might determine more precisely the meaning of these results, as the possibility of progression of unilateral MD to bilateral disease is well known. Thereby, it would be necessary to better stratify contralateral ears longitudinally and check the occurrence of dynamic alterations in the anatomical findings reported according to the progression of the disease. As a result, it might be possible to establish the role of the anatomical variations as markers of disease progression or risk factors for the development of bilateral MD, in case of significant identification of these variations, late or precociously in the follow-up of contralateral ears that would become affected over time. Experimental and histopathological studies might define more clearly the existence of pathophysiological links between anatomical factors and the incidence of MD, which remain elusive.

\section{Conclusion}

Some anatomical variations of the temporal bone might be more frequently found in routine CT scans from affected ears of patients with MD, such as the lower rates of individualization of the vestibular aqueduct. Nonetheless, according to the literature, ${ }^{25}$ the use of the imaging study of the vestibular aqueduct as a supportive diagnostic tool and the role of correlated anatomical variations in the development of MD remain a controversial issue. Longitudinal controlled studies including patients with anatomical variations possibly related to MD might be important to observe if they develop the disease more frequently over time.

Note

This paper has been chosen to be presented in the IFOSENT World Congress, which was held in Paris, in June of 2017.

\section{References}

1 Sajjadi H, Paparella MM. Meniere's disease. Lancet 2008;372 (9636):406-414495

2 Meniere P. Maladies de l'oreille interne offrant des symptomes de la congestion cerebral apoplectiforme. Gaz Med de Paris 1961;16:88

3 da Costa SS, de Sousa LCA, Piza MR. Meniere's disease: overview, epidemiology, and natural history. Otolaryngol Clin North Am 2002;35(03):455-495

4 Schessel DA, Minor LB, Nedzelski J. Meniere's disease and other peripheral vestibular disorders. In: Gaertner RS, Murphy MB, ed. Cummings Otolaryngology Head and Neck Surgery. 4th ed. Philadelphia: Mosby; 2004:3231-3232

5 da Costa SS. Central causes of vertigo. In: Souza SD, Claussen C, ed. Modern concepts of neurology. Mumbai: Prajakta Arts; 1997: 310-331

6 Paparella MM, da Costa SS, Fox R, Yoo TH. Meniere's disease and other labyrinthine diseases. in: Paparella MM, Shumrick DA, Gluckmann J, Meyerhoff WL, ed. Otolaryngology. 3rd edn. WB Saunders, Philadelphia1991:1689-1714

7 Paparella MM. The cause (multifactorial inheritance) and pathogenesis (endolymphatic malabsorption) of Meniere's disease and 
its symptoms (mechanical and chemical). Acta Otolaryngol 1985; 99(3-4):445-451

8 Harcourt J, Barraclough K, Bronstein AM. Meniere's disease. BMJ 2014;349:g6544

9 Perez-Garrigues H, Lopez-Escamez JA, Perez P, et al. Time course of episodes of definitive vertigo in Meniere's disease. Arch Otolaryngol Head Neck Surg 2008;134(11):1149-1154

10 Balkany TJ, Sires B, Arenberg IK. Bilateral aspects of Meniere's disease: an underestimated clinical entity. Otolaryngol Clin North Am 1980;13(04):603-609

11 Lopez-Escamez JA, Carey J, Chung WH, et al; Classification Committee of the Barany Society; Japan Society for Equilibrium Research; European Academy of Otology and Neurotology (EAONO); Equilibrium Committee of the American Academy of OtolaryngologyHead and Neck Surgery (AAO-HNS); Korean Balance Society. Diagnostic criteria for Menière's disease. J Vestib Res 2015;25(01):1-7

12 Jackler RK, Dillon WP, Schindler RA. Computed tomography in suppurative ear disease: a correlation of surgical and radiographic findings. Laryngoscope 1984;94(06):746-752

13 Paparella MM, Sajjadi H. The significance of the lateral sinus in Meniere's disease. in: J Nadol, ed. Proceedings of the 2nd International Symposium on Meniere's Disease, pathogenesis, pathophysiology, diagnosis and treatment. Kugler \& Ghedini Publishers, Amsterdam; 1989:139-146

14 Brook CD, Buch K, Kaufmann M, Sakai O, Devaiah AK. The Prevalence of High-Riding Jugular Bulb in Patients with Suspected Endolymphatic Hydrops. J Neurol Surg B Skull Base 2015;76(06):471-474

15 Wadin K, Thomander L, Wilbrand H. Effects of a high jugular fossa and jugular bulb diverticulum on the inner ear. A clinical and radiologic investigation. Acta Radiol Diagn (Stockh) 1986;27(06):629-636

16 Rauch SD, Xu WZ, Nadol JB Jr. High jugular bulb: implications for posterior fossa neurotologic and cranial base surgery. Ann Otol Rhinol Laryngol 1993;102(02):100-107

17 Woo CK, Wie CE, Park SH, Kong SK, Lee IW, Goh EK. Radiologic analysis of high jugular bulb by computed tomography. Otol Neurotol 2012;33(07):1283-1287

18 Vachata P, Petrovicky P, Sames M. An anatomical and radiological study of the high jugular bulb on high-resolution CT scans and alcohol-fixed skulls of adults. J Clin Neurosci 2010;17(04): 473-478

19 Kuhn MA, Friedmann DR, Winata LS, et al. Large jugular bulb abnormalities involving the middle ear. Otol Neurotol 2012;33 (07):1201-1206

20 Friedmann DR, Eubig J, Winata LS, Pramanik BK, Merchant SN, Lalwani AK. Prevalence of jugular bulb abnormalities and resultant inner ear dehiscence: a histopathologic and radiologic study. Otolaryngol Head Neck Surg 2012;147(04):750-756
21 Park JJ, Shen A, Keil S, Kuhl C, Westhofen M. Jugular bulb abnormalities in patients with Meniere's disease using highresolution computed tomography. Eur Arch Otorhinolaryngol 2015;272(08):1879-1884

22 Redfern RE, Brown M, Benson AG. High jugular bulb in a cohort of patients with definite Ménière's disease. J Laryngol Otol 2014;128 (09):759-764

23 Ikeda M, Sando I. Endolymphatic duct and sac in patients with Meniere's disease. A temporal bone histopathological study. Ann Otol Rhinol Laryngol 1984;93(6 Pt 1):540-546

24 Welling DB, Clarkson MW, Miles BA, et al. Submillimeter magnetic resonance imaging of the temporal bone in Meniere's disease. Laryngoscope 1996;106(11):1359-1364

25 Alvarenga EHL, Cruz OLM, Yamashita HKL, Lima EJ, Alvarenga AM, Bisinoto SMB. Sistematização do estudo anatômico do aqueduto vestibular por tomografia computadorizada de alta resolução em pacientes com doenças de Ménière unilateral. Radiol Bras 2006; 39(05):345-349

26 Conlon BJ, Gibson WPR. Meniere's disease: the incidence of hydrops in the contralateral asymptomatic ear. Laryngoscope 1999;109(11):1800-1802

27 Brookes GB, Morrison AW, Richard R. Unilateral Meniere's disease: is the contralateral ear normal? Am J Otol 1985;6(06): 495-499

28 Kariya S, Cureoglu S, Fukushima H, et al. Histopathologic changes of contralateral human temporal bone in unilateral Ménière's disease. Otol Neurotol 2007;28(08):1063-1068

29 Friberg U, Stahle J, Svedberg A. The natural course of Meniere's disease. Acta Otolaryngol Suppl 1984;406:72-77

30 Gürkov R, Pyykö I, Zou J, Kentala E. What is Menière's disease? A contemporary re-evaluation of endolymphatic hydrops. J Neurol 2016;263(Suppl 1):S71-S81

31 Pyykkö I, Nakashima T, Yoshida T, Zou J, Naganawa S. Meniere's disease: a reappraisal supported by a variable latency of symptoms and the MRI visualisation of endolymphatic hydrops. BMJ Open 2013;3(02):e001555

32 Karatas A, Kocak A, Cebi IT, Salviz M. Comparison of Endolymphatic Duct Dimensions and Jugular Bulb Abnormalities Between Meniere Disease and a Normal Population. J Craniofac Surg 2016; 27(05):e424-e426

33 Hall SF, O'Connor AF, Thakkar CH, Wylie IG, Morrison AW. Significance of tomography in Meniere's disease: periaqueductal pneumatization. Laryngoscope 1983;93(12):1551-1553

34 Park JJ, Shen A, Keil S, Kraemer N, Westhofen M. Radiological findings of the cochlear aqueduct in patients with Meniere's disease using high-resolution CT and high-resolution MRI. Eur Arch Otorhinolaryngol 2014;271(12):3325-3331 